\title{
PROSES PEMBUATAN ARANG BATOK KELAPA DAN TULANG SAPI MENGGUNAKAN METODE PIROLISIS SEBAGAI MEDIA CARBURIZING
}

\author{
Tumpal Ojahan'), Miswanto ${ }^{1)}$ dan Slamet Sumardi') \\ 1)Jurusan Teknik Mesin, Fakultas Teknik, Universitas Malahayati \\ ${ }^{2}$ Balai Penelitian Teknologi Mineral LIPI Lampung \\ e-mail: tumpal_ojahan@yahoo.com
}

\begin{abstract}
Fueled by a rise in food needs as beef and oil into basic commodities has been consumed by the public, has lead the increasing of waste the cows and coconut shell. The main ingredient used in this research is a waste product from cow bones and from the remains of the coconut shells from which no or household wastes, that can be processed into charcoal. The purpose of this research which is to enhance economic value of waste from cow bones and coconut shells using combustion pyrolysis system being charred (fixed carbon) to produce good quality charcoal, to find out the extent of the temperature used and the composition of charcoal. The process used in this research is pack carburizing with cow bones and coconut shell as the media at the temperature $950^{\circ} \mathrm{C}$, time detention three hours with variations composition charcoal. It can be concluded that charcoal bone across his cattle and charcoal coconut can be used as a source of carbon that might improve the force and hardness in the material carbon steel low (low carbon steel). The process of pack carburizing can increase the value of \% C, against low carbon steel material.
\end{abstract}

Keywords: coconut shell, beef bone, charcoal making, Calculation fixed carbon, pack carburizing.

\section{PENDAHULUAN}

Buah kelapa mempunyai hasil sampingan, salah satu berupa tempurung yang dapat diolah menjadi arang, namun selama ini tempurung kelapa hanya digunakan sebagai bahan bakar untuk memasak atau dibiarkan sebagai limbah. Untuk meningkatkan produk dan nilai ekonomi limbah kelapa, perlu dilakukan pemanfaatan tempurung kelapa untuk diolah menjadi arang. Limbah yang dapat dimanfaatkan selain tempurung kelapa adalah tulang sapi yang diperoleh dari sisa-sisa pemotongan para peternak sapi. Hal tersebut dapat dijadikan sebagai landasan dalam penelitian ini yang bertujuan untuk meningkatkan kadar karbon serta kekuatan dan kekerasanlogam. Adapun cara yang akan dilakukan dalam penelitian ini adalah metode pack carburizing menggunakan media arang batok kelapa dan arang tulang sapi. Berdasarkan permasalan tersebut maka penulis dapat membantu, mengurangi serta memanfaatkan limbah batok kelapa dan limbah tulang sapi yang telah dijadikan arang serta memenuhi unsur karbon yang akan digunakan sebagai media pack carburizing.

Menurut Ahmad (2007), temperatur dan waktu proses pack carburizing dapat meningkatkan kekerasan dan ketahanan spesimen yang diuji, terbukti pada penelitian yang dilakukan dengan temperatur $850^{\circ} \mathrm{C}, 900^{\circ} \mathrm{C}$, dan $950^{\circ} \mathrm{C}$ menggunakan media arang kayu dan waktu penahanan selama 6 jam [1]. Menurut Pramuko dan Purboputro (2006), waktu penahanan pada proses pack carburizing sangat berpengaruh terhadap nilai kekerasan, kadar karbon, kedalaman difusi yang dicapai bertambah, waktu penahanan 3 jam kandungan unsur karbon 0,259\%, 4 jam kandungan karbon 0,352\%, 7 jam kandungan karbon 0,505\%, serta 8 jam kandungan karbon 0,808\% [2].

Menurut Ibnu (2007), proses pack carburizing dengan media quench air akan menghasilkan kekerasan yang lebih baik dan struktur yang halus [3]. Hal ini terbukti berdasarkan landasan diatas menunjukkan bahwa untuk meningkatkan kadar karbon pada baja perlu dilakukan proses heattreatment dengan metode pengarbonan zat padat (pack carburizing). Sumber karbon dapat diperoleh dari arang batok kelapa dan arang tulang sapi. Pengujian laboratorium yang akan dilakukan adalah untuk mendapatkan arang tulang sapi dan arang batok kelapa memiliki unsur karbon yang memadai untuk digunakan sebagai media carburizing. Pengertian carburizing yaitu penambahan karbon terhadap permukaan baja yang didapat dari bahan-bahan yang mengandung karbon. Dari penjelasan tersebut maka arang tulang sapi dan arang batok kelapa dapat digunakan sebagai media pack carburizing untuk meningkatkan kekerasan pada baja. Konsep dari carburizing tersebut ditunjukkan pada Gambar 1. 


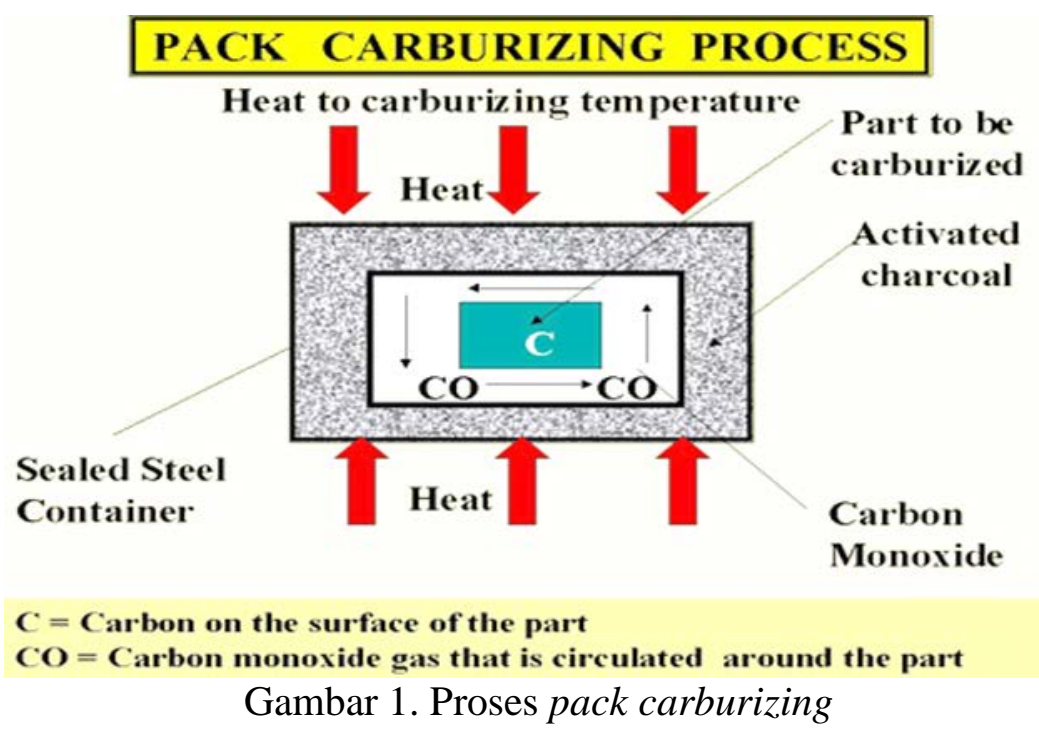

Tahap ekstraksi karbon dari zat padat yang perlu dilakukan yaitu benda kerja yang akan dikarbonisasi dimasukkan ke dalam kotak karbonisasi yang sebelumnya sudah diisi media karbonisasi, selanjutnya benda kerja ditimbun dengan bahan karbonisasi dan benda kerja lain diletakkan diatasnya demikian selanjutnya. Kandungan karbon dari setiap jenis arang adalah berbedabeda. Semakin tinggi kandungan karbon dalam arang, maka penetrasi karbon ke permukaan baja akan semakin baik pula.

Sebenarnya tanpa ditambah bahan karbonat, karbonisasi masih dapat terjadi karena temperatur yang tinggi ini mula-mula karbon teroksidasi oleh oksigen dari udara yang terperangkap dalam kotak menjadi karbon dioksida $\left(\mathrm{CO}_{2}\right)$. Reaksi yang terjadi adalah

$\mathrm{CO}_{2}+\mathrm{C}$ (arang) $\longrightarrow 2 \mathrm{CO}$

Dengan temperatur yang semakin tinggi kesetimbangan reaksi makin cenderung ke kanan menunjukkan semakin banyak kandungan CO.

$2 \mathrm{CO} \longrightarrow \mathrm{CO}_{2}+\mathrm{C}$ (larut ke dalam baja)

\section{METODE PENELITIAN}

Penelitian dilakukan menurut diagram alir penelitian pada Gambar 2.

\section{Alat yang digunakan untuk membuat arang}

Pembuatan arang dilakukan dengan pembakaran sistem pirolisis. Sistem pirolisis yaitu pembakaran dengan membatasi oksigen yang ada di dalam ruang/tempat pembakaran itu sendiri serta menghilangan sebagian zat yang ada didalam arang seperti kadar air, zat pengotor dan kadar abu. Alat yang digunakan dalam pembakaran ini adalah drum dan kaleng kecil yang diberi lubang pada bagian atas dan samping, lubang ini berfungsi sebagai ruang udara agar pada saat pembakaran berlangsung oksigen yang terperangkap dalam drum/kaleng bisa keluar sehingga pembakaran dapat berlangsung dengan baik. Alat yang digunakan dalam pembuatan arang dapat dilihat pada Gambar 3. Proses pembuatan arang ditunjukkan pada Gambar 4 dan Gambar 5. 


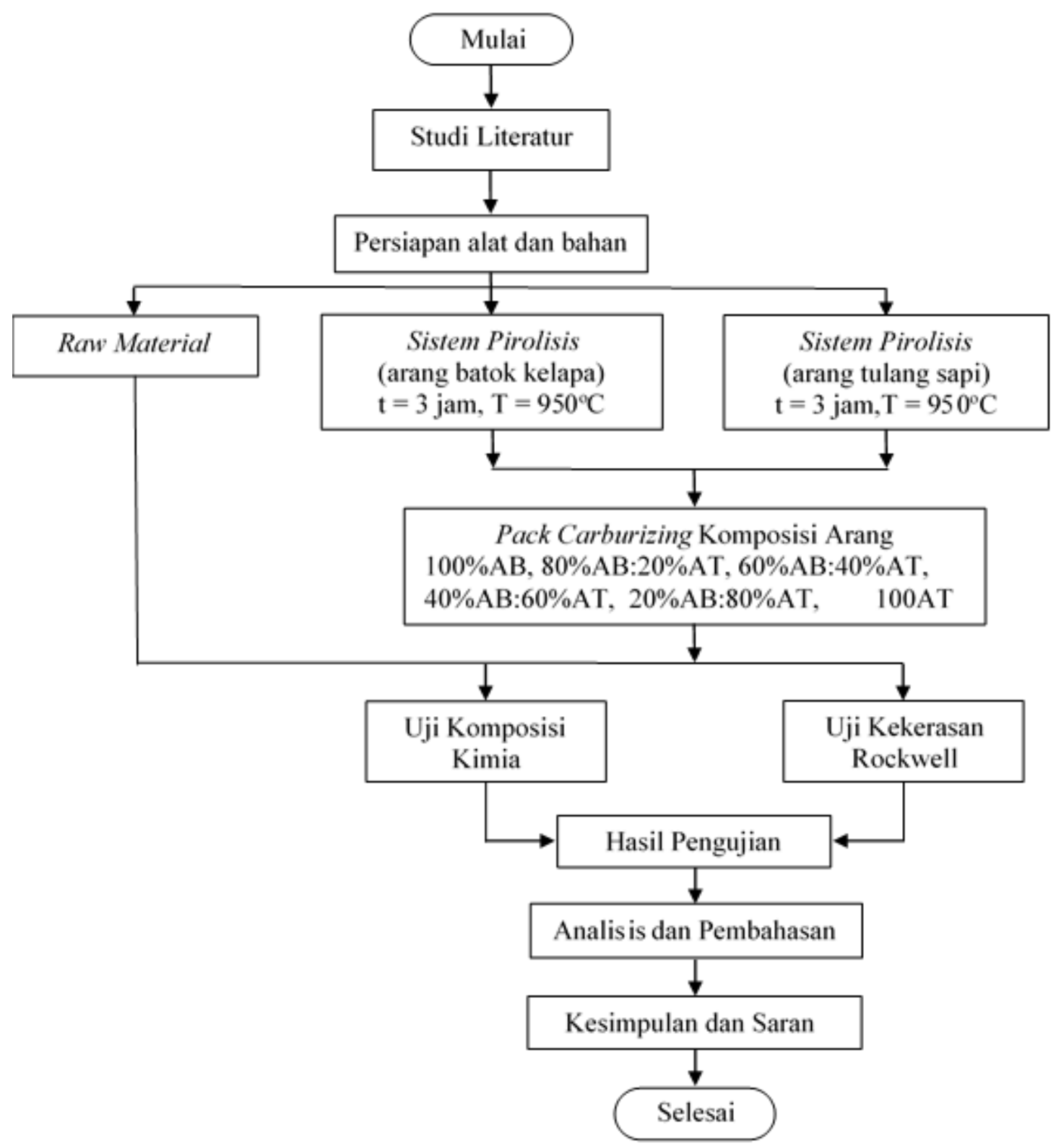

Gambar 2. Tahapan penelitian

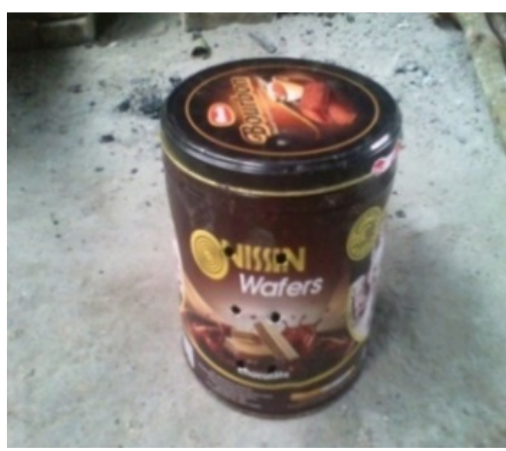

(a)

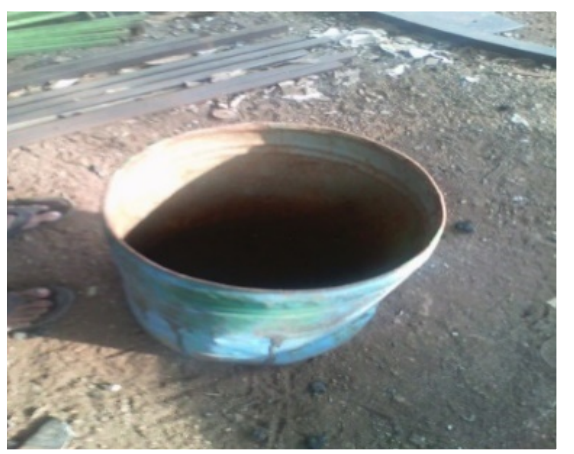

(b)

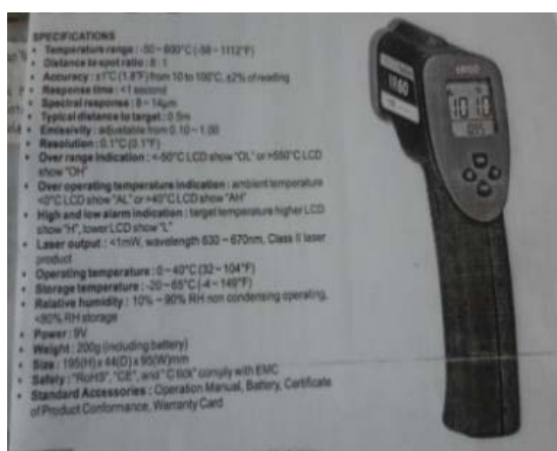

(c)

Gambar 3. Sistem pirolisis.

((a). Kaleng tempat pembuatan arang batok kelapa. (b). Drum tempat pembuatan arang tulang sapi. (c). Thermometer untuk mengukur suhu pembuatan arang) 


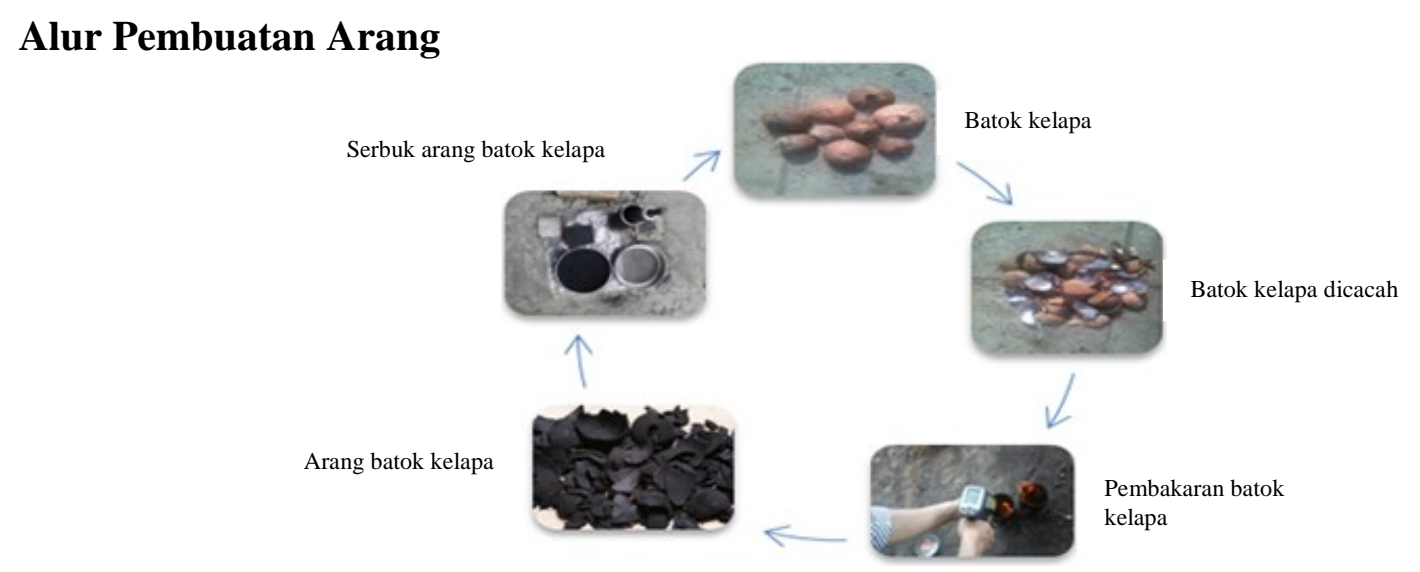

Gambar 4. Alur pembuatan arang batok kelapa

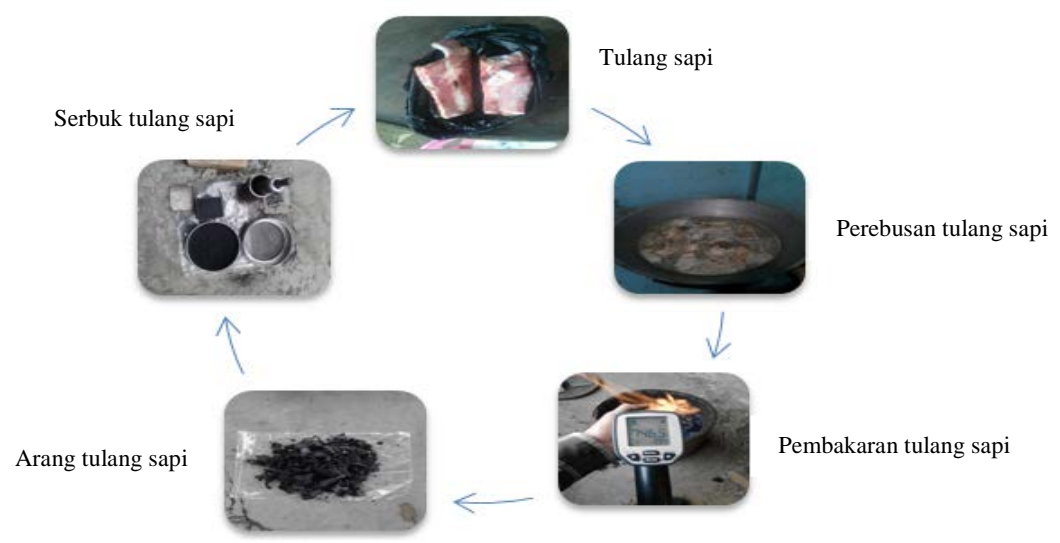

Gambar 5. Alur pembuatan arang tulang sapi

Tabel 1. Berat tulang sapi dan batok kelapa sebelum dan sesudah arang

\begin{tabular}{lcccc}
\hline \multicolumn{1}{c}{ Pembakaran } & $\begin{array}{c}\text { Berat Tulang Sapi dan } \\
\text { Batok Kelapa (kg) }\end{array}$ & $\begin{array}{c}\text { Hasil Arang } \\
\text { (kg) }\end{array}$ & $\begin{array}{c}\text { Waktu Pembakaran } \\
\text { (menit) }\end{array}$ & $\begin{array}{c}\text { Rendemen } \\
\text { (\%) }\end{array}$ \\
\hline Arang Tulang Sapi & 9 & 2,50 & 330 & 27,78 \\
Arang Batok Kelapa & 8 & 1,16 & 279 & 29,12 \\
\hline
\end{tabular}

\section{HASIL DAN PEMBAHASAN}

\section{Pembuatan Arang Batok Kelapa}

Pembuatan arang batok kelapa yang dilakukan dalam penelitian ini melewati lima tahapan yaitu menyiapkan batok kelapa, kemudian batok kelapa dipecah untuk mempermudah dan mempercepat pembakaran, pembakaran batok diikuti dengan pengamatan waktu dan temperatur, menimbang hasil arang setelah pembakaran dan menghitung total karbon. Prinsip pembuatan arang batok kelapa yaitu pembakaran dengan sistem suplai udara terkendali, proses pembakaran dikendalikan dengan cara mengatur suplai udara ke dalam tabung tempat pembakaran. Pada bagian tempurung yang sudah terbakar menjadi arang, lubang suplai udara ditutup dan lubang pada baris bagian atasnya dibuka sehingga proses pembakaran hanya berlangsung pada bagian yang lubang suplai udaranya terbuka. Begitu seterusnya sampai lubang udara pada baris paling atas. Dengan demikian, arang yang dihasilkan dari pembakaran ini memiliki rendemen yang bagus yaitu 29,12\% dan kadar air 6,5\%. Dalam proses pembakaran dilakukan pengamatan temperatur dan waktu, hal ini bertujuan untuk mengotrol berjalannya proses pembakaran agar pembakaran bisa berjalan dengan baik, mengetahui waktu dan temperatur yang dicapai. Alat yang digunakan untuk membaca temperatur yaitu thermometer yang mampu membaca temperatur mulai $200^{\circ} \mathrm{C}$ sampai $2400^{\circ} \mathrm{C}$. Untuk pengamatan waktu dan temperatur yang dilakukan dapat dilihat pada Tabel 2. 


\section{Pembuatan Arang Tulang Sapi}

Arang tulang sapi yang digunakan pada penelitian ini diperoleh melalui enam tahapan yaitu tahap penyiapan tulang sapi, pembersihan, pengeringan, pemotongan dan pembakaran, penimbangan arang hasil pembakaran dan perhitungan total karbon. Terlebih dahulu tulang sapi disiapkan sesuai dengan kebutuhan untuk proses pengarbonan zat padat (pack carburizing), setelah tulang sapi diperoleh kemudian dibersihkan dan dikeringkan dibawah terik matahari dengan temperatur $30^{\circ} \mathrm{C}$ selama 16 jam, setelah kering tulang dipecah atau dipotong sesuai dengan ukuran yang diinginkan, proses ini bertujuan memudahkan proses pembakaran dan mempercepat pembuatan arang. Setelah tulang sapi selesai dibersihkan dan dipecah, tulang sapi dimasukan kedalam kaleng kemudian di tutup, pada bagian tutup kaleng diberi lubang dengan tujuan pada saat pembakaran uap bisa keluar. Prinsip pembuatan arang tulang sapi pada dasarnya sama dengan pembuatan arang batok kelapa, pengamatan temperatur pembuatan arang tulang sapi menggunakan alat thermometer yang bertujuan untuk mendapatkan data dan mengontrol dalam pembuatan arang, langkah ini dilakukan agar arang tidak sampai menjadi abu. Untuk pengamatan waktu dan temperatur yang dilakukan dapat dilihat pada Tabel 2.

Berdasarkan Tabel 1, hasil penelitian menunjukkan bahwa waktu yang dibutuhkan untuk $9 \mathrm{~kg}$ tulang sapi yang dibakar sampai menjadi arang yaitu 330 menit dan berat arang yang diperoleh adalah $2,5 \mathrm{~kg}$, dengan rendemen yang dihasikan dari pembakaran tulang sapi yaitu 27,78\%. Sementara hasil penelitian menunjukkan bahwa waktu yang dibutuhkan untuk 8 kg batok kelapa yang dibakar sampai menjadi arang yaitu 279 menit dan berat arang yang diperoleh adalah 1,16 kg, dengan rendemen yang dihasikan dari pembakaran tulang sapi yaitu $29,12 \%$.

Tabel 2. Pengamatan temperatur dan waktu arang tulang sapi dan batok kelapa

\begin{tabular}{cccc}
\hline \multicolumn{2}{c}{ Arang Batok Kelapa } & \multicolumn{2}{c}{ Arang Tulang Sapi } \\
\hline Waktu & Temperatur $\left({ }^{\circ} \mathbf{C}\right)$ & Waktu & Temperatur $\left({ }^{\circ} \mathbf{C}\right)$ \\
\hline 09:00-10:00 & 219 & $08: 30-11: 00$ & 213 \\
10:00-11:00 & 264 & $11: 00-11: 30$ & 294 \\
11:00-12:00 & 294 & $11: 30-12: 00$ & 329 \\
12:00-13:00 & 344 & $12: 00-12: 30$ & 400 \\
13:00-13:30 & 410 & $12: 30-13: 00$ & 490 \\
13:30-13:45 & 450 & $13: 00-13: 30$ & 541 \\
& & $13: 30-14: 00$ & 746 \\
\hline
\end{tabular}

\section{Proses Mendapatkan Fixed Carbon}

Untuk Mendapatkan Fixed Carbon pada arang batok kelapa dan arang tulang sapi maka perlu dilakukan pemanasan ke dalam furnace, setelah melewati tahapan pemanasan maka arang batok kelapa dan arang tulang sapi dapat dihitung kadarnya yang meliputi kadar air total, kadar air lembab, zat terbang, kadar abu, kemudian akan didapat total karbon yang terdapat pada arang. Cawan dan timbangan digital yang digunakan untuk mendapatkan total karbon pada arang. Proses perhitungan kadar unsur dilakukan di laboratorium seperti pada Gambar 6.

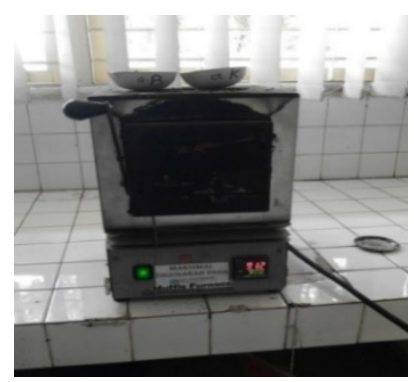

(a)



(b)



(c)

Gambar 6. (a). Tungku pemanas (furnace), (b). Cawan, (c). Timbangan digital 


\section{Fixed Carbon Arang Batok Kelapa}

1. Analisis Kadar Air Total (SNI 13-376-1994)

Rumus: $\operatorname{mar}(\%)=\frac{m 2-m 3}{m 2-m 1} \times 100$

$$
\begin{array}{rlrl}
\mathrm{A} & =\left(\frac{27,46-26,66}{27,46-14,11}\right) \times 100 & \mathrm{~B} & =\left(\frac{23,04-22,29}{23,04-12,58}\right) \times 100 \\
& =\frac{0,8}{13,35} \times 100 & & =\frac{0,75}{10,46} \times 100 \\
& =6 \% & & =7,17 \%
\end{array}
$$

Nilai rata-rata $=\frac{6+7,17}{2}=6,5 \%$

2. Analisis Kadar Air Lembab (SNI 3477-2:2017)

$$
\begin{array}{rlrl}
\text { Rumus: } \operatorname{mad}(\%)=\frac{m 2-m 3}{m 2-m 1} \times 100 & & \\
\text { A } & =\left(\frac{26,66-26,67}{26,66-17,7}\right) \times 100 & \mathrm{~B} & =\left(\frac{22,29-22,24}{22,29-13,31}\right) \times 100 \\
& =\frac{0,01}{8.96} \times 100 & & =\frac{0,05}{8,98} \times 100 \\
& =0,11 \% & & =0,55 \%
\end{array}
$$

Nilai rata-rata $=\frac{A+B}{2}=\frac{0,11+0,55}{2}=0,33 \%$

3. Analisis Zat Terbang (Volatile): (SNI 13-3999-1995)

Rumus: volatile $(\%)=\frac{m 2-m 3}{m 2-m 1} \times 100$

$$
\begin{aligned}
\mathrm{A} & =\left(\frac{24,40-24,24}{24,40-23,40}\right) \times 100 \\
& =\frac{0,16}{1} \times 100 \\
& =16 \%
\end{aligned}
$$

$$
\begin{aligned}
\mathrm{B} & =\left(\frac{22,39-22,27}{22,39-21,39}\right) \times 100 \\
& =\frac{0,12}{1} \times 100 \\
& =12 \%
\end{aligned}
$$

Nilai rata-rata $=\frac{A+B}{2}=\frac{16+12}{2}=14 \%$

4. Analisis Kadar Abu (SNI 3478: 2010)

Rumus: kadar abu $(\%)=\frac{m 3-m 1}{m 2-m 1} \times 100$

$$
\begin{aligned}
\mathrm{A} & =\left(\frac{35,93-35,91}{36,41-35,91}\right) \times 100 \\
& =\frac{0,02}{0,5} \times 100 \\
& =4 \%
\end{aligned}
$$

$$
\begin{aligned}
B & =\left(\frac{36,07-36,06}{36,56-36,06}\right) \times 100 \\
& =\frac{0,01}{0,5} \times 100 \\
& =2 \%
\end{aligned}
$$

Nilai rata-rata $=\frac{A+B}{2}=\frac{4+2}{2}=3 \%$

5. Analisis Kadar Karbon Tertambat (Fixed Carbon): (SNI 13-3479-1994)

Rumus: Fc $(\%)=100-($ mad + kadar abu + volatile $)$

$$
\begin{aligned}
& =100-(0,33+14+3) \\
& =100-17,33 \\
& =82,67 \%
\end{aligned}
$$

Arang batok kelapa yang akan digunakan sebagai media pack carburizing terlebih dahulu dilakukan perhitungan kadar air total dengan nilai rata-rata yang didapatkan yaitu 6,5\%, kadar air lembab dengan nilai rata-rata $0,33 \%$, zat terbang dengan nilai rata-rata $14 \%$, kadar abu dengan nilai rata-rata $3 \%$, setelah dilakukan tahapan tersebut maka didapatkan nilai total karbon (fixed carbon) arang batok kelapa yaitu 82,67\% C. 


\section{Fixed Carbon Arang Tulang Sapi}

1. Analisis kadar air total (SNI 13-376-1994)

Rumus: $\operatorname{mar}(\%)=\frac{m 2-m 3}{m 2-m 1} \times 100$

$$
\begin{array}{rlrl}
\mathrm{A} & =\left(\frac{31,43-31,27}{31,43-21,43}\right) \times 100 & \mathrm{~B} & =\left(\frac{33,41-33,26}{33,41-23,41}\right) \times 100 \\
& =\frac{0,16}{10} \times 100 & & =\frac{0,16}{10} \times 100 \\
& =1,6 \% & & =1,5 \%
\end{array}
$$

Nilai rata-rata $=\frac{A+B}{2}=\frac{1,6+1,5}{2}=1,55 \%$

2. Analisis Kadar Air Lembab (SNI 13-3477-1994)

Rumus: $\operatorname{mad}(\%)=\frac{m 2-m 3}{m 2-m 1} \times 100$

$$
\begin{array}{rlrl}
\mathrm{A} & =\left(\frac{31,27-31,23}{31.27-21.43}\right) \times 100 & \mathrm{~B} & =\left(\frac{33,26-33,23}{33,26-23,41}\right) \times 100 \\
& =\frac{0,04}{9,84} \times 100 & & =\frac{0,03}{9,85} \times 100 \\
& =0,40 \% & & =0.30 \%
\end{array}
$$

Nilai rata-rata $=\frac{A+B}{2}=\frac{0,40+0,30}{2}=0,35 \%$

3. Analisis Zat Terbang (Volatile): (SNI 13-3999-1995)

Rumus: volatile $(\%)=\frac{m 2-m 3}{m 2-m 1} \times 100$

$$
\begin{array}{rlrl}
\mathrm{A} & =\left(\frac{22,43-22,26}{22,43-21,43}\right) \times 100 & \mathrm{~B} & =\left(\frac{24,42-24,23}{24,42-23,42}\right) \times 100 \\
& =\frac{0,17}{1} \times 100 & & =\frac{0,16}{1} \times 100 \\
& =17 \% & & =16 \%
\end{array}
$$

Nilai rata-rata $=\frac{A+B}{2}=\frac{17+16}{2}=16,5 \%$

4. Analisis kadar abu (SNI 3478: 2010)

Rumus: kadar abu (\%) $=\frac{m 3-m 1}{m 2-m 1} \times 100$

$$
\begin{array}{rlrl}
\mathrm{A} & =\left(\frac{23,79-23,41}{23,91-23,41}\right) \times 100 & \mathrm{~B} & =\left(\frac{21,86-21,44}{21,94-21,44}\right) \times 100 \\
& =\frac{0,38}{0,5} \times 100 & & =\frac{0,42}{0,5} \times 100 \\
& =76 \% & & =84 \%
\end{array}
$$

Nilai rata-rata $=\frac{A+B}{2}=\frac{76+84}{2}=80 \%$

5. Analisis Kadar Karbon Tertambat (Fixed Carbon): (SNI 13-3479-1994)

Rumus: Fc $(\%)=100-($ mad + kadar abu + volatile $)$

$$
\begin{aligned}
& =100-(0,35+80+16,5) \\
& =100-96,85 \\
& =3,15 \%
\end{aligned}
$$

Keterangan:

$\mathrm{m} 1$ = Berat cawan kosong (gram)

$\mathrm{m} 2$ = Berat cawan + sampel (gram)

$\mathrm{m} 3$ = Berat cawan + sampel setelah dipanaskan (gram)

mar $=$ Kadar air total pada sampel 
Tabel 3. Kandungan kimia pada arang

\begin{tabular}{lcc}
\hline Komposisi Kimia & $\begin{array}{c}\text { Arang Tulang Sapi } \\
(\mathbf{\% )}\end{array}$ & $\begin{array}{c}\text { Arang Batok Kelapa } \\
\mathbf{( \% )}\end{array}$ \\
\hline Kadar Air Total & 1,55 & 6,50 \\
Kadar Air Lembab & 0,35 & 0,33 \\
Zat Terbang & 16,50 & 14,00 \\
Kadar Abu & 80,00 & 3,00 \\
Total Karbon (fixed carbon) & 3,15 & 82,67 \\
\hline
\end{tabular}

Total karbon (fixed carbon) arang tulang sapi yang didapatkan dari hasil perhitungan memiliki nilai \%C yang kecil, namun tulang sapi terdapat kandungan kalsium phospat dan kalsium karbonat yang cukup tinggi.

Tabel 4. Kandungan komposisis kimia tulang sapi [4]

\begin{tabular}{ll}
\hline Chemical Components & Amount Present (\%) \\
\hline Organic component & - \\
Collagen, muco-polysacharides, elastin and fat & 30,00 \\
Inorganic component & - \\
Calcium phosphate (calcium hydroxylapatite) & 38,25 \\
Calcium carbonate and trace ions & 6,75 \\
Water & 25,00
\end{tabular}

Tabel 5. Penimbangan spesimen sebelum dan sesudah dilakukan pack carburizing

\begin{tabular}{|c|c|c|c|c|c|}
\hline $\begin{array}{c}\text { Temperatur } \\
\left({ }^{\circ} \mathrm{C}\right)\end{array}$ & $\begin{array}{l}\text { Waktu } \\
\text { (jam) }\end{array}$ & Komposisi Arang & $\begin{array}{c}\text { Berat Awal (Wo) } \\
\text { (gram) }\end{array}$ & $\begin{array}{c}\text { Berat Akhir (Wi) } \\
\text { (gram) }\end{array}$ & $\begin{array}{c}\text { Selisih Berat (WC) } \\
\text { (gram) }\end{array}$ \\
\hline \multirow{5}{*}{950} & \multirow{5}{*}{3} & $100 \% \mathrm{AB}$ & 36,92 & 37,00 & 0,08 \\
\hline & & $80 \% \mathrm{AB}+20 \% \mathrm{AT}$ & 36,96 & 37,16 & 0,20 \\
\hline & & $60 \% \mathrm{AB}+40 \% \mathrm{AT}$ & 36,58 & 36,72 & 0,17 \\
\hline & & $40 \% \mathrm{AB}+60 \% \mathrm{AT}$ & 36,63 & 36,79 & 0,16 \\
\hline & & $100 \% \mathrm{AT}$ & 36,25 & 36,37 & 0,12 \\
\hline
\end{tabular}

Dari Tabel 5 menunjukan hasil penimbangan spesimen sebelum dan sesudah dilakukan karburisasi terlihat bahwa terjadi penambahan karbon terhadap spesimen yang telah dilakukan karburisasi. Pada temperatur $950^{\circ} \mathrm{C}$ penambahan karbon yang signifikan terlihat pada komposisi arang $80 \%(\mathrm{AB})+20 \%$ (AT) dengan nilai penambahan 0,20 gram. Penambahan berat ini dipengaruhi oleh temperatur selama proses pengkarbonan, dimana temperatur media karborisasi terurai menjadi gas CO yang selanjutnya terurai menjadi karbon aktif yang dapat berdifusi masuk ke dalam spesimen sehingga berat spesimen menjadi naik [2].

\section{Uji Komposisi Kimia Logam}

Tabel 6. Komposisi kimia sebelum dan sesudah dilakukan pack carburizing.

\begin{tabular}{|c|c|c|c|c|c|c|c|c|c|}
\hline \multirow{2}{*}{$\begin{array}{c}\text { Temperatur } \\
\left({ }^{\circ} \mathrm{C}\right)\end{array}$} & \multirow{2}{*}{$\begin{array}{l}\text { Waktu } \\
\text { (Jam) }\end{array}$} & \multirow{2}{*}{ Komposisi Arang } & \multicolumn{7}{|c|}{ Unsur Logam (\%) } \\
\hline & & & Fe & C & Si & Mn & $\mathbf{P}$ & $\mathbf{S}$ & $\mathrm{Cr}$ \\
\hline \multirow[t]{3}{*}{$R M$} & & & 98,3 & 0,106 & 0,157 & 0,769 & 0,021 & 0,016 & 0,112 \\
\hline & & $100 \% \mathrm{AB}$ & 97,5 & 1,00 & 0,148 & 0,683 & 0,013 & 0,016 & 0,106 \\
\hline & & $80 \% \mathrm{AB}+20 \% \mathrm{AT}$ & 97,5 & 1,05 & 0,153 & 0,656 & 0,013 & 0,015 & 0,100 \\
\hline \multirow[t]{3}{*}{950} & 3 & $60 \% \mathrm{AB}+40 \% \mathrm{AT}$ & 97,4 & 1,08 & 0,151 & 0,672 & 0,014 & 0,017 & 0,112 \\
\hline & & $40 \% \mathrm{AB}+60 \% \mathrm{AT}$ & 97,4 & 1,09 & 0,147 & 0,666 & 0,016 & 0,017 & 0,094 \\
\hline & & $100 \% \mathrm{AT}$ & 97,4 & 1,12 & 0,159 & 0,686 & 0,016 & 0,024 & 0,105 \\
\hline
\end{tabular}




\section{Uji Kekerasan Rockwell (HRc)}

Material yang telah melewati proses pack carburizing dilakukan pengujian Rockwell, hal ini untuk melihat perubahan kekerasan yang terjadi pada material sebelum dan sesudah mengalami proses pack carburizing. Kekerasan material sebelum dan sesudah dilakukan proses pack carburizing mengalami peningkatan. Apabila dilihat variasi komposisis arang dengan maka nilai \%C yang terbesar terdapat pada komposisis 100\% AT.

Tabel 7. Uji kekerasan rockwell (HRc) dengan berbagai komposisi arang

\begin{tabular}{lclc}
\hline Temperatur $\left({ }^{\mathbf{O}} \mathbf{C}\right)$ & Waktu (Jam) & Komposisi Arang & Uji Kekerasan Rockwell (HRc) \\
\hline RM & & $100 \% \mathrm{AB}$ & 57,15 \\
& & $80 \% \mathrm{AB}+20 \% \mathrm{AT}$ & 64,20 \\
950 & \multirow{2}{*}{3} & $60 \% \mathrm{AB}+40 \% \mathrm{AT}$ & 61,89 \\
& & $40 \% \mathrm{AB}+60 \% \mathrm{AT}$ & 61,58 \\
& & $100 \% \mathrm{AT}$ & 61,03 \\
\hline
\end{tabular}

Berdasarkan data yang diperoleh dari pengujian kekerasan Rockwell (HRc) pada material dasar mempunyai nilai kekerasan $57,15 \mathrm{kgf} / \mathrm{mm}^{2}$, sedangkan material yang sudah dilakukan pack carburizing menunjukan nilai kekerasan yang meningkat antara 61,03-64,20 kgf $/ \mathrm{mm}^{2}$. Analisis nilai kekerasan pada temperatur $950^{\circ} \mathrm{C}$ menunjukan nilai kekerasan semakin bertambah yang berada pada komposisi arang $100 \%$ AB yaitu 64,20 kgf $/ \mathrm{mm}^{2}$.

\section{SIMPULAN}

1. Pembakaran dengan sistem pirolisis mengasilkan arang yang berkualitas dengan rendemen arang batok kelapa 29,12\%, dan rendemen arang tulang sapi 27,78\%.

2. Waktu yang dibutuhkan dalam pembuatan arang batok kelapa yaitu 285 menit dengan suhu yang dicapai $450^{\circ} \mathrm{C}$ dan waktu untu pembuatan arang tulang sapi yaitu 330 menit dengan suhu yang capai $746^{\circ} \mathrm{C}$.

3. Arang batok kelapa mempunyai kadar air total 6,5\%, kadar air lembab 0,33\%, zat pengotor $14 \%$, kadar abu 3\%, dan fixed carbon yang dihasilkan yaitu 82,67\%C.

4. Arang tulang sapi mempunyai kadar air total $1,55 \%$, kadar air lembab $0,35 \%$, zat pengotor $16,5 \%$, kadar abu 80\%, dan fixed carbon yang dihasilkan yaitu 3,15\%C.

5. Nilai kekerasan raw material sebelum dilakukan proses pack carburizing $57,15 \mathrm{kgf} / \mathrm{mm}^{2}$ sedangkan nilai kekerasan setelah dilakukan proses pack carburizing mengalami peningkatan antara $61,03 \mathrm{kgf} / \mathrm{mm}^{2}$ sampai dengan $64,20 \mathrm{kgf} / \mathrm{mm}^{2}$.

\section{DAFTAR PUSTAKA}

[1] Ahmad, AS., 2007, "Pengaruh Suhu Carburizing Menggunakan Arang Batok Kelapa Terhadap Kekerasan dan Ketahanan Aus Roda Gigi Baja Aisi 4140”. Skripsi, Fakultas Teknik Universitas Negri Semarang 2007, Semarang.

[2] Pramuko, I., dan Purboputro, 2006, "Pengaruh Penahanan Terhadap Sifat Fisis dan Mekanis pada Proses Pengarbonan Padat Baja Mild Steel”. Jurnal Media Mesin, Vol. 7, No. 1, Hal. 916, Januari 2006, Universitas Muhammadiah Surakarta, Surakarta.

[3] Ibnu, KP., 2007, "Perbedan Nilai Kekerasan pada Proses Double Hardening dengan Media Pendingin Air dan Oli Sae 20 pada Baja Karbon Rendah”.Skripsi, Universitas Negri Semarang, Semarang.

[4] Ihom, AP., 2013, “Case Hardening of Mild Steel using Cowbone as energiser”. African Journal of Engineering, Vol. 1, PP. 97-101, October 2013, University Of Uyo, Nigeria.

[5] BPTP (Balai Pengolahan Teknologi Mineral) Lampung. 2016. Analisis Perhitungan Fixed Carbon Pada Arang.

[6] Callister, 2009, “Materials Science and Engineering An Introduction Eight Edition”. Wiley, 
USA.

[7] Mujiyono dan Arianto, LS., 2008, "Meningkatkan Efektifitas Karburisasi Padat pada Baja Karbon Rendah dengan Optimasi Ukuran Serbuk Arang Tempurung Kelapa”. Jurnal Teknik Mesin, Vol. 10, No. 1, Hal. 8-14, April 2008, Universitas Negri Yogyakarta, Yogyakarta.

[8] Rustan, H., 2011, "Sosialisasi Teknik Pembuatan Arang Tempurung Kelapa dengan Pembakaran Sistem Suplai Udara Terkendali”. Buletin Teknik Pertanian, Vol. 16, No. 2, Hal. 77-80, 2011, Litbang BPTP Jambi.

[9] Schonmetz A. dan Gruber. K., 1985, "Pengetahuan Bahan dalam Pengerjaan Logam” Angkasa, Bandung.

[10] Surdia Tatadan Shinroku, S., 2000, “Pengetahuan Bahan Teknik”. PT. Pradnya Paramitha Edisi kelima, Jakarta.

[11] Tumpal Ojahan R., 2010, “Perlakuan Panas dan Permukaan”. Diktat Perkuliahan, Fakultas Teknik Program Studi Teknik MesinUniversitas Malahayati, Bandar Lampung.

[12] Vlack, VLH., dan Djaprie, S., 1991, “Ilmu dan Teknologi Bahan”. Erlangga, Jakarta. 